\title{
A DISCOURSE
}

\section{O N S T A T E M E D I C I N E. Delivered before the University of Dublin, April 6th, 1872 .}

By WV I L I A M S T OKE S, M.D., D.C.L., F.R.S., Regius Professor of Physic.

I PROPOSE, in this discourse, to draw the attention of my hearers to a subject which is every day growing in importance, and claiming a larger share of public attention in England, in India, and in America. It is that of State Medicine, which comprises Legal and Preventive Medicine, and, in fact, embraces the whole of sanitary science.

It has been proposed to consider State Medicine under the heads I have just mentioned. With the subject of Legal Medicine, or Medical Jurisprudence, I need not at present detain my hearers, but will proceed to Preventive Medicine, which is mainly a growth of our own time. It may be described or defined as that body of knowledge of many kinds which deals with the causes of the physical evils of the human race, with a view to their prevention or their mitigation.

Sanitary science is related more particularly to Preventive, as distinguished from Curative Medicine. The one deals with causes; the other with effects, which in their turn become causes. Now, if we compare the relative importance of these two branches of medical knowledge, a greater value must be attached to the first than to the second; and for this reason-that the well-being of larger numbers of mankind depends immeasurably more on Preventive than on Curative Medicine.

The great end of the one is to preserve the health of the masses of mankind, so as to diminish the necessity of the other. The one calls to its assistance the study of all social defects, together with that of many of the greater phenomena of nature. It is to be furthered by large and wise legislation; while the other is dependent on the slow and intermitting advance of purely medical knowledge, as well as on the individual attainments of those who are to apply it. Preventive Medicine embraces everything, as is well shown by the Regius Professor of Medicine at Oxford, which relates to the physical and moral well-being of our fellow-men; so that it has to contend with all moral, social, and physical evils. Ignorance, selfishness, the grinding of the poor, the consumption of human life like fuel for the production of wealth, vicious indulgence, and everything that deteriorates the body, and with it the mind, come within its extended scope. Its object is the health, and therefore the happiness and prosperity, of man; its instruments are science and common sense, with rules plain and patent to all; so that it promises to be the noblest pursuit yet offered to the human intellect, and he would be a bold man who would dare to limit its results or to predicate its triumphs.

The extent and magnitude of the subjects embraced under the head of Preventive Medicine are so great, that it is difficult for the mind at once to form an adequate idea of them. Everything that influences the physical condition of man, directly or indirectly (and this latter brings in the moral question), be it for good or for evil, is to be studied in relation to the great subject before us. All the laws as to the action of external or of internal agents on his birth, development, health, strength, and longevity, are to be considered; the influence of age, sex, race, and hereditary transmission of disease ; of occupations, especially those that, although they are unwholesome, have become indispensable from modern requirements. The social and moral standard of populations, and their birth and death rates at different times and in different places-in other words, their vital and sanitary statistics-are required ; so also the effects of personal cleanliness, and, conversely, the accumulation of filth in our dwellings, highways, and byeways, and the results of overcrowding - that fertile source of disease and demoralisation.

Though the spread of epidemics cannot as yet be referred to simple meteorological considerations, every phenomenon of meteorology must be studied in relation to the health of man. Every variation of atmospheric electricity, or of terrestrial and siderial magnetism, as indicated by Humboldt; the pressure, temperature, and hygrometric state of the atmosphere-all require to be investigated with the same view; so also do the laws of synthesis in organic chemistry, as in relation to the influence of the ingesta, and, it may be, to the origination of disease.

But there is more to be said. The laws of epidemical and of endemical disease, and the manner in which they arise, have yet to be worked out; so also the correlation, and perhaps even the convertibi- lity, of zymotic affections. This bears on the germ-theory, lately revived, but as yet not handled with the modesty of science. "Does like in disease always produce like?" is a question to be asked. The whole subject of contagion, and the application of the doctrine of probabilities to its proof or disproof ; the variations in the state of receptivity of the body; and the influence of the law of periodicity on diseases, whether as regards the world-wide pestilence or the individual case-all require elucidation.

Finally, it is a question for Preventive Medicine, whether disease results from any original or natural law of our being, or is its preordination by the Almighty a punishment for the neglect of His laws? Can a true civilisation, which means the employment of the results of observation, bring about or restore that state of the human constitution, that normal condition in which, under the beneficent and immutable law of periodicity, the life of man should run its appointed course, the vital chain be at once broken, and the soul forced the nearest way, without suffering and without disease?

All this to help in solving the question-How is public health to be best maintained, so as to escape the influences which deteriorate it, and prevent the progressive physical and moral decay, not of the individual man alone, which there is reason to fear is going on in England, but in communities of men? To ascertain, to proclaim, and, in God's own time, to clear away the lets and hindrances which everywhere prevail to the working out of the laws of the All-wise and All-powerful, for the well-being and the happiness of His creatures-laws which are every day lost sight of through that public ignorance, immorality, and selfishness which, making all things subservient to the lust for gold, constitute the real danger to these countries.

For many years the subject of public health has been slowly but steadily attracting attention in England, and this, at first, was mainly owing to the enlightened labours and perseverance of one distinguished physician and philanthropist, Dr. Rumsey. There is no part of the subject which his pen has not tended to elucidate. In one of his works he gives an account of a private meeting of a small number of friends, at which it was determined that each of them should labour to bring the matter before the national mind. From that time the subject of public health has advanced in general estimation; and now, from being but little thought of, except in the way of ridicule and as a dream of enthusiasts, it holds a large place in the minds of the thinking men of the British dominions, whether legislators, political economists, or men of science.

Previously to 1867 , when the British Medical Association was invited by this University to hold its annual meeting within the walls of Trinity College, much had already been done in England. I have spoken of the labours of Dr. Rumsey, which so thoroughly entitle him to the national gratitude, and were then acknowledged by the University of Dublin in conferring upon him, with some other distinguished men who on that occasion visited Ireland, the degree of Doctor of Medicine, honoris causî. On the report of the Public Health Committee of the Association, of which he was chairman, being brought up, it was proposed by Dr. Acland that a deputation of representatives of the Association and of the Social Science Congress should urge upon the Government the propriety of taking the matter in hand, with a view to legislation.

The Public Health Act was passed in 1858 , when the powers of the Privy Council were enlarged so as to deal with a variety of sanitary questions; and the reports of its distinguished medical officer, which embrace almost every topic of Preventive Medicine, form by themselves a work of reference upon the subject. The British Medical Association and the Social Science Congress worked together for the same purpose, while many of the towns and villages of England and Scotand obtained the benefit of sanitary reform in various degrees.

In 1868, the General Medical Council appointed a committee to in quire into, and to report on, the steps proper to be taken (if any) for granting diplomas or certificates in State Medicine, and for recording the same in the Medical Register, due regard being had to the interests of existing health-officers in the several parts of the kingdom. The resolution was forwarded to a number of eminent authorities, at home and abroad, inviting them to favour the Council with their views on the subject. Their answers are published in the second Report of $\mathbf{I} 869$. Among the correspondents in Great Britain and Ireland, were the Lord Chancellor and the Lord Chief Justice of England ; Sir William Jenner; Dr. Farre; Dr. Symonds ; Mr. Simon; Professor Haughton; Mr. Hewlett, the energetic Health-Officer of Bombay; Dr. Alfred Taylor and Professor Travers; while among the foreign correspondents there were Rokitansky, Pettenkofer, Pappenheim, and Varrentrapp.

With reference to the qualification in State Medicine, the Council had before it the question, suggested by Mr. Simon, and adopted by Dr. Rumsey, as to whether, in cases where an university degree was 
unattainable, a qualification should emanate from the Council itself. The Committee agreed that the thorough discussion of the question of appointments and duties in the Public Medical Civil Service had be. come essential for the progress of social administration and organisation, so that students or practitioners, however few they might be, should be able to obtain a diploma certifying the possession of knowledge adequate to the end in view. They were unanimously of opinion that the Council should insert the requisite clauses for providing a qualification in State Medicine in any amended Bill which might hereafter be prepared for Parliament. In accordance with the course urged upon the Government by the deputation from the societies I have mentioned, a Royal Commission was, in the first instance, named, after some delay, to inquire into the sanitary state of these countries. Then came a change of Ministry ; but a Commission was finally appointed under the chairmanship of Sir Charles Adderley, and it was determined -I think wisely - to limit the inquiry in the first instance to England. The Report of this Commission was presented to the Houses of Parliament last year.

Two local Government Acts, necessarily the precursors of the Sanitary Act, have been introduced; and we may now look for a compresive statute in which the confused mass of the sanitary laws of these countries will be arranged and codified. Let me specify some of the leading recommendations of the Commission.

It is proposed that the country should be divided into areas or dis. tricts, each with its local authority for preserving the public health. That for all public health purposes no area should be without an authority of this kind, or have more than one such. That, instead of the present permissive system, under which it rests to a great extent with the local authorities to adopt or neglect the provisions of the existing law, those of the new statute should be, with certain exceptions, obligatory. That in each district the local administration for public health and for Poor-law relief should be in the hands of the same authority. That the central authority for the administration of the laws concerning the public health, and also poor-law relief, should be vested in one Minister of the Crown, whose title should signify that he has charge of both departments. He should have full powers of supervision and inspection, of control and direction, over all local authorities. His charge should be of two distinct though correlative departments. That every local health-authority should have at least one officer of health, and that in the rural districts the Poor-law medical officers should be the officers of health within their respective districts. That their election should be subject to the veto of the Minister, and their removal impossible without his sanction. That special inspectors and referees with engineering, medical, chemical, and legal knowledge, would be required by the central authority. That inducements should be provided for the study of State Medicine.

The importance of such an enactment, the leading features of which I have given you in outline, must be obvious to all. It will place the preservation of the public health on a sure foundation by bringing the local authorities under a central head, and thereby preventing the evils which flow from the ignorance, indifference, caprice, and the undefined constitution of the local authorities. It will place the question of public health on the basis of accumulative scientific observation; and, last, though hardly least, it will act in elevating the status of that noble and devoted band of men who do Christ's work of healing among the poor.

In a memorandum drawn up by three members of the Commission, and printed in the first Report, the following observations occur.

"The advantages are many. Not only will the plan be efficient and complete, but it will be economical. The work of the Local Government, I,aw and Engineering Departments, of the Registrar-General, of the Poor-law Board, and of the Privy Council, will be harmonised, and will never be chargeable with repetitions and omissions as at present, while neither money nor skill will be wasted.

"All reports bearing on public health will be connected one with the other, mutually illustrating each other. They will cover the whole ground of the science of prevention of disease, which has become both so important and so serious for the well-being of old and densely peopled countries. The connexion of the office of Minister of Health with the medical profession, four thousand members of which will be in direct relation to him, would in itself be beneficial to the whole country. It would disseminate combined scientific knowledge uni. formly through the rural districts, affecting not the medical men only, but the clergy and the schools, doing in that way alone as much at least as direct legislation for the same purpose could do. It would bring to light, in every corner, all that could be advanced as bearing on the physical condition of masses of the people, while all crude theories and impracticable plans would instantly fade before the expe-
The proposal to employ the Poor-law medical officers as officers of health has been objected to by some able writers, on two grounds principally ; one, that the education of these gentlemen has not been suffi. cient to enable them to deal with questions of State Medicine, and the other, that from their too often dependent position in relation to members of local boards, they will be crippled as to their action for the public good. This last objection would, I believe, apply far less to Ireland than to England. But granting that they have some founda. tion, what is the proper way of meeting them?

It may be admitted that in many rural districts the education of the dispensary medical officer, sufficient to qualify him for being placed on the Register, is often so completely technical that he cannot do more than deal with curative medicine as he best may. Should such a man be called to report on questions of State Medicine, he will probably be found, at first at least, defective. But necessity is a great instructor, and it is in the nature of things that he will every year improve. Selfeducation can do wonders. He will be assisted by skilled inspectors, and his good sense, probity, and honourable ambition will do the rest.

With respect to the second objection, if it be true, so much the worse for all parties. But there are better times coming. The dispensary surgeon will be placed in a higher and more secure position, from having to perform duties which are related, not to his district solely, but to the public weal. He will be in communication with the Minister, as it were inter instrumenta regni, not like the Roman poisoner of old for purposes of evil, but for those of good, and cannot be displaced without his sanction. Therefore he will in time be treated with greater con. sideration, and the country will come to perceive that professional honour implies public safety.

It is clear that similar Commissions, with a view to sanitary legislacase demanding similar legislation for the three for if ever there was a public health. The machinery of the law may require to be varied in the three kingdoms as regards local authorities and areas of taxation, but sanitary science is the same for all men. In this respect England is far in advance of us, both as to the knowledge and as to the practical application of the laws of public health. In Ireland, the habits of the poor as to uncleanliness and overcrowding call for great reform, especially in our towns, where poverty, neglect, and overcrowding so often make them foci of endemical disease. The condition of our country towns and villages is simply deplorable, disgraceful to the local authorities, and in too many instances to the proprietary, frequently heedless as to the social and physical condition of those who live under them. Even the state of the metropolis, possessing a Public Health Committee, is shocking, as has been ably shown by Dr. Grimshaw in a recent communication. Let me read some extracts of a letter from a gentleman of great ability and truthfulness, who holds an important public appointment in the south of Ireland. He had been requested by the Town Commissioners of a certain place in that part of the country to inspect the state of the town, and report on the works necessary for sewage improvement. It was about the year 1865 , when there was some apprehension of an epidemic of cholera.

"I went," says this gentleman, "through every lane and street, and examined all the tenements of every class, in the latter end of January. or beginning of February. There were no main sewers in any but the principal streets, and none of these had them for their whole length. The lanes and alleys leading off from these streets were mostly very narrow, and had no outfalls for sewerage discharge except surface-channels, and very few of the houses had any back entrance; a good many had neither yards nor back entrances. But all had dung-pits. If not behind, they were contrived in the widest parts of the lanes by being sunk and enclosed with walls, so as to hold from eight to twelve cubic yards of manure each. Where the tenement had not the 'easement' of a dung-pit or yard, or right to part of the common way, the manure was stored in the dwelling-house. Most of the houses were thatched cabins, but several rows of two-storied houses were built, and a good many onestoried slated houses of small size were to be found containing four apartments. I discovered in one of these rows, which had very small back yards (not half the size of the house in any case), that the whole of the ground-floor and part of the house, except the staircase and passage leading to it, were filled with manure (the scrapings of the roads and streets) tightly packed to the height of eight feet; and in the rooms above there were two families living-one in each room. The manure had of course heated, and was steaming up through the chinks of a badly laid floor, the under side of which was dripping wet from the fermentation below.

"In several of the rows having back yards, the surface-water was allowed to run through the whole length of the lane from yard to yard, and the occupier of the lowest tenement was looked upon as having the most valuable holding of the whole lot; and something like the Chinese 
care of liquid manure was shown, by extra mould or refuse being provided to absorb or soak it up. The parts of the town to which this description may apply covered about twenty-five acres, and almost every part of that surface was teeming with effluvia from such decayed substances of every sort as are admitted to be of the most noxious kind, without any provision whatever for carrying off the putrid water which is always to be seen in so wet a climate as this.

"The population is about six thousand, of whom two-thirds live in cabins furnished with the inevitable dung-pit. These cabins contain seven hundred families at the least. The dung-pit averages ten cubic yards in content, so that on twenty-five acres we have at least seven thousand cubic yards of fnetid matter, with four thousand people breathing the exhalation of such an accumulation as could not, I think, be found elsewhere, even in Ireland.

"But, nevertheless, the town of Killarney has always been a remarkably healthy place. There is a fever-hospital which has not been full since the famine dysentery in $1847-48$, and which is very frequently empty. There is no dislike on the part of the poor to go into this hospital, because it is not the workhouse, so that the few fever cases that do occur are quickly removed out of the crowded houses.

"It was asked-" How can such a state of things be? or, how can it be accounted for that such good public health can exist amid all this rottenness giving rise to the miasmata so well known as certain producers of fever and cholera ?' I suggested that there were two great advantages in favour of health, namely: an ample supply of the very best water, and smoky houses. The subsoil of the town is gravel and sand to a great depth, and in this there are many strong springs, the purest water being met with at six or eight feet under the surface. The fuel used is all turf, and the blackened walls of the inside of the houses showed that the inhabitants lived in an atmosphere of peat-smoke. I cannot help thinking that such smoke, possessing as we know preserving or antiseptic properties, must act as a deodoriser and preventive against infection or malaria.

"I asked one of the occupiers who lived over his dung-heap in an upper floor, how he could expect to escape death by fever or cholera to himself or some of his family (a wife and five children), and his reply was, 'Sure, we might as well be dead as never to have a bit of dung for the garden'.

"Some legislator has said that 'Ireland is an anomaly'-maybe the sanitary statistics of this town are another proof of this."

The inhabitants of this place escaped the epidemic so common in other towns of the south of Ireland, perhaps, because, in addition to the pure water and turf-smoke, an intimacy with malaria for many generations had at last made them insusceptible to it.

The influences of impure air and water, imperfect drainage, and overcrowding, have been held by sanitarians to account for the origination of epidemical or endemical disease. The subsidence of any such disease after the adoption of sanitary reform, is appealed to in evidence that it sprang from preventable causes. But the argument is defective. It is like that of the therapeutist as regards essential diseases, which run their appointed course, and then subside independently of any specific treatment. Like isolated cases of fever, epidemics have their period of invasion, maturity and decadence, and the conclusion is obvious. How many great epidemics over the world have died out before sanitary reform was ever thought of? There is in many minds a tendency to attribute great phenomena to too limited a source.

"The supposition of a single cause," says a learned writer, " is quite unsupported by nature. Every animal, every plant, every rock requires for its production the co-operation of many causes, and probably of many that we have not yet discovered. All nature depends ultimately on a single cause, but it has pleased that Almighty Cause that the effects which concern us immediately should arise from the co-operation of several of His creatures."

But the question before us is-are such influences as I have mentioned the sole or the chief causes of fever in this country? It is difficult to believe that they are; because in Ireland, not only in the isolated dwellings of the poor, which are scattered over the face of the country, but in the towns also, all those causes which result from the imperfect drainage of dwellings, from the accumulation of decomposing organic matters in their vicinity, and from imperfect ventilation, are, I regret to say, but too constant and too general ; and yet the production of fever, whether sporadically or epidemically, is inconstant or irregular in the highest degree. Why should these causes produce fever at one time and not at another? Why should districts remain for years free, or comparatively iree, from fever, while the supposed exciting causes continue in full force? Or, again, why, if the cause be constant, should the epidemic character of the fever vary? We may say, excluding the consideration of isolated cases, that each epidemic has a special or predominant character.
In the present state of our knowledge, are we to hold that preventable influences are the originators of disease? No doubt, civilisation demands that all things injurious to health, or noxious to the senses, should not be permitted to exist. But the question remains whether, leaving the origin of disease undetermined, sanitary reform does not act as much by the improvement of the health of the population, as by the lessening or extinction of the exciting causes of zymotic affections. The community being better prepared to resist the advent of disease, its spreading will be influenced and its severity lessened when it does come. This, I apprehend, is the safe and practical way of looking at sanitary reform. It is fortunate that theoretical questions in no way touch the working out of such reform. Questions as to whether the spread of cholera is influenced by the dryness or the moisture of the air ; as to the spontaneous generation of germs ; or as to whether, when the sewage of a town is spread out upon the fields, there may be a struggle for existence among various organisms, so that the cholera molecules die out-such questions only divert the attention from more important matters. The sanitary reformer is not to wait for the advent of epidemical disease. It is rather when a country is free from such, that he can best work in removing or mitigating all those causes which experience shows to act against the health of man.

No one, who has had not had a life-long experience of epidemics, can estimate the difficulties which exist as to their origin, as to the absence of essential fever in places where, theoretically, it ought to prevail. The appearance of epidemics at irregular periods, while their supposed exciting causes remain constant; their disappearance, though the causes continue in full operation; their outbreaks in all latitudes, climates, and seasons ; their different modes of spreading; the want of constancy in their symptoms and history, for every great epidemic has its own character; the varieties as to the extent, nature, and effect of the secondary affections which arise in their course; the varieties in their mode of subsidence and behaviour under treatment; their degree of mortality and contagiousness-all these things constitute the diff. culties which surround us in our investigations as to zymotic disease. They bear on the supposed specific or constant origin of disease; on the error of drawing hard and fast lines between essential affections ; and are with difficulty reconcilable with the germ-theory.

But still, though differing in history, symptoms, nature, and mortality, these essential affections have their resemblances. They are all under the influence of the law of periodicity. We do not know any treatment by which they can be cured. No man ever cured a fever, be it the yellow fever, plague, cholera, small-pox, or scarlatina. In these diseases it is simply a question of time; and, if life can be prolonged by proper support, and by meeting the secondary accidents of the disease, the patient will recover spontaneously, as it were, on the striking of the clock.

Again, these diseases are all, to a greater or less extent, contagious; a characteristic of which the best evidence is found by the application of the doctrine of chances. In the progress of an epidemic in Ireland (and doubtless, also, in other countries), in a family of twelve persons, the disease has been known to attack eleven out of the twelve. In some cases, the passing of the fever through so large a proportion as eleven individuals out of twelve, has taken a very considerable period of time, as you may readily understand. It has taken about three months to go through them all. Now, my father proposed these two problems to the then Bishop of Cloyne, Dr. Brinkley, for solution.

I. "An epidemic prevails so severely, that one person out of seven sickens. A family of twelve is selected in a particular district before the epidemic has visited it. What is the chance that eleven out of that family shall take the disease, supposing the sickness of one of the family does not promote the sickening of another-that is, supposing the disease not to be contagious, and supposing the family to be not unusually liable to the disease?"

The answer furnished by Dr. Brinkley was, that the probability against such an event is $189,600,000$ to $\mathbf{r}$. This is a very singular and extraordinary result.

2. "The same general conditions being assumed, and also that the number of inhabitants of a district is 7,000 , what is the chance that, in a family of twelve within the district, eleven will sicken ?"

Answer : "The chance then is 300,000 to $I$ that no family of twelve persons, in a population of 7,000 , will have eleven persons sick."

These numbers furnish proofs so convincing of the truth of the doctrine of contagion, that it is hardly necessary to go further. The facts on which they were based are ascertained facts ; they have been common facts in epidemic fever ; but, recollecting that they were common facts, the chances against their happening, if the disease were not contagious, would be $189,600,000$ to $I$ in the one case, and 300,000 to $I$ in the other. But we know also that any depraved state of the public health in a community renders it more liable to outbreaks of some of these 
forms of disease ; destroys the power of resistance possessed by the human body, which in the depressed state, induced through preventable causes, falls a ready prey to the pestilence.

The great end of sanitary science is to preserve intact the health of the body. In dealing with large masses of men, most of them ignorant, many of them powerless, it will not be sufficient, as Miss Nightingale well insists on, to trust to legislative enactments to do the whole work. Education must lend its aid ; and until this has acted, not only on the ignorant masses of men in this country, but on the millions of India the work of sanitary reform will be imperfectly done, though enforced by an enlightened despotism. Her remarks were made as regards India. But education is required at home, not only among the artisan and peasant classes, but in those who constitute Board of Guardians and other local authorities, to say nothing of the landed proprietors themselves.

It has redounded much to the credit of this University, so long remarkable for its faculty of reading the signs of the times, and so forward in all measures of educational improvement, that a qualification in State Medicine in connexion with Trinity College has been instituted. To obtain it, the candidate must be a Doctor in Medicine and pass a comprehensive examination. Though possessing a great medical school, Trinity College has recognised the distinction between Preventive and Curative Medicine. Upon the Court of Examiners for that qualification are the Professors of Law, Chemistry, Engineering, Natural Philosophy, Hygiene, and Medical Jurisprudence ; and the "Testamur" has been already obtained by four gentlemen, whose University career has shown that those most distinguished in medicine have been also eminent in their course of arts. Oxford, in the person of its Regius Professor of Medicine, is identified with the cause of State Medicine; and the Medical Syndicate of Cambridge have already agreed upon the subject.

It is plain that the old teaching Universities are in the best position for instruction in State Medicine; and in this place the existence of a School of Engineering, many of the pupils of which occupy important positions in various parts of the world, gives it a peculiar advantage.

It may be asked what is meant by "Sanitary Engineering"? Dr. Rumsey, in a letter with which he has favoured me, observes that the real effects of structural works on health have not been fairly ascertained. "Civil Engineers," he remarks, "have only lately begun to study the relations of the various matters of their profession to human life. The influence of different modes of construction of dwellings, roofs, drains, the size of rooms and public buildings, the effect of local drainage, the study of river and air currents, and their effect on the health of the people are not mere problems of statics and dynamics-nor are they simply questions of elegance of design, convenience of use, or durability of structure."

Let me illustrate the matter by examples. The sanitary engineer will not sink a well in places where the water may be polluted, or so construct it that it may be fouled by surface water, or by decomposition of matters thrown into it. In the year 1868, the drownings in the Bombay Presidency numbered $I, 608$. Of these, whether from accident or from suicide, I, IOI were in wells. He will have to deal with water-supply, as to its source, constancy, purity, fall, and the nature of the soil through which it runs. The whole subject of drainage and of sewerage must be familiar to him; the disposal of sewage, and its application towards fertilising the soil, to say nothing as to the proper construction, with reference to ventilation and warmth of hospitals, jails, barracks, passenger ships, and schools.

India is the country, throughout whose length and breadth for many years there has existed one vast hotbed of disease, from which epidemics have spread over Europe destroying immense numbers of victims in their course. Under the British rule sanitary reform has been at tempted, though, as yet, it is but partially carried out ; and the Health Reports of India, drawn up by the military medical staff, form in themselves a most valuable contribution to sanitary science. Miss Nightingale says, in a letter to the Bengal Social Science Association

"There is so constant a relation between the health of a people and their social civilisation that, alas! one of the best, if not the best, indications of the social state of populations is afforded by the numbers who die year by year. Nor this only, for the Almighty has so linked together the happiness and misery of all his creatures, that we in Europe can almost anticipate whether Indian cholera is to devastate the nations of the West by the number of people who are dying of it in Lower Bengal."

In the report by Dr. Townsend on the central provinces, we learn that in 1868 four thousand villages and towns with a population of nearly eighty millions were attacked by cholera ; and in a population of more than two millions nearly fifty thousand died.

The following striking picture of the condition of Central India is given in the Report of the Army Sanitary Commission for 1870. After stating that the causes connected with locality exist in most intensity in the river deltas, the Report goes on to speak of the people.

"Their houses are little better than hovels, often greatly overcrowded. .. The water-supply, whether obtained from house-wells or from tanks, appears to be very foul, and quite unfit for domestic consumption. There appear to be few or no arrangements for domestic cleanliness. Filth and refuse matters are retained in the houses or thrown out into the road. The people themselves are poor, apathetic, underfed, sickly, indisposed for much exertion, filthy in their clothing and habits; their clothing scarcely sufficient to guard against alternations in temperature. The landed proprietors appear to take little interest in their health. The people are decimated year after year by epidemics, or rather by endemics, of fever, cholera, and other diseases of miasmatic origin; or their usefulness to the State is diminished or destroyed by the permanent consequences of these diseases. Their only resource under these afflictions appears to be temporarily running away from the villages; and, when matters become too bad for endurance, they leave the village altogether, and build another on new ground with immediate benefit to health. It is a striking proof of the influence of careless occupation of a locality in deteriorating its sanitary condition, even in districts eminently unhealthy, that the population decreases in old, and increases in new, villages. After a time, in new villages the old course is resumed, disease and mortality increase, other changes of habitation are sought, and this appears to have been going on from generation to generation."

Now, since the introduction of sanitary measures, the death.rates of the three great capitals and of the jails over the continent of India are stated to have greatly lessened. Calcutta shows better than Liverpool or Manchester, and the death-rate of Bombay is less than that of London. Yet Bombay is peculiarly exposed to the importation of disease from the annual influx of multitudes of pilgrims from all parts of Asia on their way to the tomb of the Prophet at Mecca, and on their return. It is stated by Mr. Hewlett that Bombay could be kept free or almost free from zymotic diseases, but for their importation by the crowds of pilgrims. To those who have not had a long personal experience of India, it is not easy to estimate the difficulties which that country presents as to almost every matter relating to State Medicine. Take the subject of sanitary or even vital statistics. Competent authorities hold that the published death-rates are but partially reliable, not from any mala fides on the part of the reporters, but from this, that, notwithstanding the weight of English authority, it has not overcome the determined hostility of the natives of both the prevalent religions to the registration of births and deaths. The family of a Hindoo or Moslem is a sanctum which no English official must penetrate or examine too minutely. Deaths of children or women in the Janana are not admitted by the natives to be concerns of the governing power; and the lower castes skilfully evade too minute inquiries; so that it seems probable that the published death-rates cannot be trusted within four or five per thousand. In a minute of the Army Sanitary Commission, we find it mentioned that, with the exception of the three capitals, there is no indication of the presence of the sanitary engineer in any village, town, or city throughout India, and that the Commission is sorry to say there are examples in the Report of so-called sanitary works, which had better never been executed. In illustration of this, I have been informed that the vast sewers lately made in Calcutta are laid in ground of alluvial deposits-most of it soft and yielding like quicksand-and therefore not likely to maintain their proper levels and falls, or to preserve their structural integrity. It is to be feared that they may, accordingly, become in time nothing but elongated cesspools, with an uncertain and ever-changing outlet at the one end, and at the other opening into thousands of houses.

Looking at these facts and at the social degradation of the village communities of India, what a fertile field does India present for engineering talent, were it only applied for the purposes of public health! What an opportunity for putting in force all the appliances for preventive medicine and its consequent social improvement! There are the hundreds of millions of subjects to the British Crown, whose domestic habits seems little better than those of the lowest animals-one living wide-spread mass of wretchedness, the examples of moral and physical degradation and decay, the recurring sources of destruction to the farremoved and nobler inhabitants of the earth.

It will not be amiss to reflect on the altered state of things which may result from the larger application of the principles of State and Preventive Medicine in a more advanced condition of society. I shall not seek to draw any picture of a moral or a medical Utopia, but surely we may hope that some measure of good will follow the search for truth, when the inquirers look for it earnestly - that is, when they seek for it with all the aids that science affords. Every immediate and remote cause of 
moral and physical evil must be investigated and, if possible, removed. National health will be found to be connected with national morality and prosperity. We in our time cannot expect to solve all the problems which will be presented to us, but if a few are successfully handled, we shall be thankful for the instalment. Every man in his own person may assist in removing those evils which afflict society, and even his very diseases may be made to fructify for the common good. The great instruments of Preventive Medicine will be science, legislative wisdom, and charity-that blessed and fragrant flower of the following of Christ. War, that assimilates man to the brutes, will become more odious as its collateral effects will be better understood. In the war of liberation of Spain, we have the authority of Sir Gilbert Blane in stating that more of our soldiers died of fever than of ali other causes, including the sword.

A time may come when the conqueror of disease will be more honoured than the victor in a hundred fights. The time may come when no man for his own ends, or for his profit, will be permitted to damage the health or the well-being of his neighbour or of his servant, nor the prisoner have to suffer through the ignorance or the indifference of his jailer a greater penalty than was awarded by the law, while the emigrant with his loved ones will be protected from disease as he expatriates himself from the land of his birth. The gifts to man from Heaven -pure air, pure water, bright light, and wholesome food, will be more freely shared in, and the moral and physical evils of overcrowding, and the consequent guilt, the shame, the pestilence, will disappear. The artisan will be taught the dangers of his particular calling, and so far as law and public opinion go, be protected from them; whether he labour in a hot room, amid the roar of machinery, or deep in the earth where he has to work in passages carved by himself of little more than two feet in height, inhaling the smoke of gunpowder and particles of silex till his working life comes to an untimely and miserable end.

That false morality which would ignore the existence of, and therefore would neglect, that unhappy class of the victims of society, will be denounced and exposed. Infant life, concerning the preservation of which civilised England may well take her lesson from Russia, will be protected by the State.

The power of science will be brought home to all men, as to everything that can influence health, food, drink, labour, residence, occupa. tion ; and,"as it touches each of these considerations, will lead mankind to higher thoughts and purer lives.

The principles of the science of public health will be taught in our Universities, and from them downwards in our elementary schools; and the influence and the light of science be brought to bear upon all men.

Think of the nillions of our fellow-men-brethren, subjects of the same crown, at home or on the burning plains of India, contending miserably with, or yielding to, the multiplied evils of degradation, and consequently untimely death, from whom the ignorance of their rulers as well as of themselves keeps the light of knowledge; and you will admit that it is a noble object for those who dwell in, and who govern, the homes of science-our ancient teaching Universities of these countries, to prepare and to send out over the world their disciplined and devoted soldiers of science and of ethics, with the highest academical, and therefore social, rank, to contend with and abate those moral and physical evils, the growth of ages, the offspring of ignorance, which so long have afflicted and retarded mankind.

REAL IRISH WHISKY IN THE NORTH OF IRELAND. AT the last meeting of the Chemico-Agricultural Society of Ulster, at Belfast, under the presidency of Dr. Knox, late Poor-law Inspector, the subject of whisky-adulteration was brought under consideration by Mr. Hodges, who exhibited a specimen of that liquid brought to him by two men who had been physically incapacitated by drinking a small portion of it in a publichouse. He $\mathrm{fcund}$, on analysis, that it contained a large amount of naphtha. He had also discovered that ingredients of even a more deleterious character were used in the pro. cess of adulteration-mixtures containing sulphate of copper, cayenne pepper, sulphuric acid, and a little spirits of wine. One specimen submitted to Dr. Hodges by a number of provision cutters and curers was composed of naphtha and a slight colouring of whisky. The men who had imbibed a small quantity of it were simultaneously affected with serious symptoms; and this, said Dr. Hodges, was a fair specimen of the drink sold in low-class public-houses. The trade in this noxious compound is carried on with impunity; no local authorities in Belfast or in the province of Ulster caring to exercise the powers with which the legislature has invested them for the suppression of the traffic.

\section{CLINICAL LECTURES}

ON

\section{STRA N GULATED HER N IA.}

Dilivered at St. Bartholomew's Hospital.

Bi SIR JAMES PAGET, BART., F.R.S., Consulting Surgeon to the Hospital.

LeCture I.-Concluded.

2. Let me now go on to speak of the guidance to be derived from the remoter symptoms ; and, first, from the inaction of the bowels. This inaction, or rather this hindrance of expulsion, is a nearly constant sign in strangulated hernia, but occurs in so many other cases that its sole presence is of little weight among motives for operating. Its absence is, rather, that which needs study.

One or more actions of the bowels, after other signs of strangulation have set in, are of no weight at all against the propriety of operating. They commonly occur, because usually after strangulation the part of the bowel below the constricted part empties itself. These actions of the bowels are not to be counted on either side of the question about reducibility or operation; and even a regular and frequent action is not an absolute prohibition, for the strangulation may involve only omentum, or only a part of the circumference of a portion of intestine. In these conditions, freces may pass along the canal and be discharged.

I had to see a lady for what was considered an abscess in her groin. The swelling was just over the femoral ring, and contained fluid and air. I punctured it, and let out pus and air and liquid fæces, and presently I found a piece of hernial sac sloughed off and lying in the abscess. This, and the history of the case, proved that the hernia had, about a week previously, descended when the patient felt a sudden pain while driving. The hernia was so small that it was overlooked; its pain and the griping which it caused were thought due to colic, and were so treated. The bowels acted sufficiently, and gradually the little hernial sac and its enclosed piece of the intestinal wall died and sloughed off. Then came the signs of abscess over the femoral ring, and its outlet; and this was followed by complete healing and many years of health.

However, such cases as this are very rare ; and you may hold by the general rule, that you should not operate when the bowels act frequently or regularly, unless all the other signs of strangulation, both local and remote, be well marked.

3. The state of the abdomen is as little or less decisive in cases in which you may be in doubt. Of course, if it be sensitive and tender on pressure, either everywhere or in parts near the hernia, still more if it be distended and the muscles hard, this is an addition to the reasons for operating, and, I may add, to the reasons for fearing that you may be too late. It is more to be remembered that, when the abdomen is not tense or tender, when it may even feel nearly natural, yet you must operate if other signs of strangulation be present, and the hernia cannot be put back. For the changes of the abdomen are not common near the beginning of strangulation, and to wait for them would often be to wait till toolate.

4. If I were asked which of the signs of strangulation I would most rely on as commanding the operation, I should certainly say the vomiting. Time after time, when the other signs were feebly, if at all, marked, the vomiting has been a sufficient guide to a timely operation. Many times, when all else was so quiet that it seemed rash to operate, the vomiting proved that it would have been much more rash to wait; and not one instance can I find in my notes in which neglect of the import of vomiting was not proved to be unwise. You had better hold the rule complete, that, when a patient has a hernia, recently become irreducible, and, with this, vomiting which cannot be clearly assigned to something independent of the hernia, you should operate. I am obliged to say recently become irreducible, because a patient with an old irreducible hernia may vomit, as any one else may, without any reason for suspecting strangulation; though in even these old cases you must be very watchful lest the vomiting be an early sign of strangulation. But the rule is safe that recent irreducibility and vomiting are enough to justify the operation, even though there be no other signs of strangulation present. Much more must the operation be deemed necessary when with these the other signs of strangulation, in even slight degrees, coincide.

And in thus judging of the vomiting, do not be too scrupulous as to its manner or its products. There are indeed some notable modes 